\section{Matters arising}

\section{Respiration and sleep in Parkinson's disease}

Sir: We read with interest the report by Apps et al. ${ }^{1}$ We should like to describe our own recent experience reported elsewhere, ${ }^{2}$ which has some similarities but also some important differences.

There is some evidence that patients with Parkinson's disease die more frequently during sleep than those with other neurological diseases, ${ }^{3}$ suggesting possible respiratory insufficiency. Flow-volume loop abnormalities have also been described in awake patients which are consistent with reversible upper airways obstruction. ${ }^{4}$ For these reasons we decided to document sleep physiology in 10 patients with idiopathic Parkinsonism and to compare them with 10 patients with post-encephalitic Parkinsonism, in whom sleep abnormalities have long been recognised, ${ }^{5}$ and 20 age- and sexmatched controls. Bedside screening tests of autonomic function were performed in all subjects and no abnormalities were present.

Like Apps et al, we noted a significant reduction in the duration and proportion of REM sleep in our patients, which was most marked in those with post-encephalitic Parkinsonism (Group 3); less marked in the six patients with Hoehn \& Yahr stage III-IV patients with idiopathic Parkinsonism receiving optimal levodopa therapy (Group 2); and least marked in four patients with mild (stage I-II), untreated idiopathic Parkinsonism (Group 1). However, all patients had more frequent episodes of obstructive and central sleep apnoea than controls, most frequent in Group 2 (see table). Apnoeic episodes were predominantly $(>80 \%)$ obstructive/mixed in nature, but central apnoeic episodes were also recorded in all patient groups and were of similar frequency in groups 2 and 3 . In addition, one patient in Group 1 had recurrent episodes of obstructive sleep apnoea in REM and non-REM sleep for more than two hours each night, accompanied by arterial oxygen desaturation of 5-25\%, and therefore fulfilled the accepted criteria ${ }^{6}$ for the sleep apnoea syndrome. Interestingly this patient was not obese, consistently had a normal flow-volume loop when awake, and had no other respiratory abnormalities. This is of particular significance since both Parkinson's disease and obstructive sleep apnoea syndrome are said to be associated with abnormalities of the flow-volume loop in many patients.

Whilst we acknowledge that there may be differences of methodology and of semantics in defining "significance" of apnoeic episodes ${ }^{7}$ between our own study and that of Apps et al, our own data suggest that significant respiratory abnormalities during sleep may be just as frequent in idiopathic and post-encephalitic Parkinsonism of comparable severity. This raises important questions about possible more extensive neurological deficits, for example affecting the brainstem, in Parkinson's disease. Further studies are clearly warranted.

RJ HARDIE

J EFTHIMIOU

GM STERN

Department of Neurology University College Hospital London WCIE 6AU, UK

\section{References}

1 Apps MCP, Sheaff PC, Ingram DA, Kennard C, Empey DW. Respiration and sleep in Parkinson's disease. J Neurol Neurosurg Psychiatry 1985;48:1240-5.

2 Efthimiou J, Ellis SJ, Hardie RJ, Stern GM. Sleep apnoea in idiopathic and postencephalitic Parkinsonism. Read to the Eighth International Parkinson's Disease Symposium, New York, June 1985 (Proceedings in press, Advances in Neurology series, Raven Press, New York).

3 Riederer $\mathbf{P}$, Wuketich $\mathbf{S}$. Time course of nigrostriatal degeneration in Parkinson's disease. J Neural Trans 1976;39:257-61.

4 Vincken WG, Gauthier SG, Dollfus RE, Hanson RE, Daruay DM, Casio MG. Involvement of the upper airway muscles in extrapyramidal disorders. New Engl $J$ Med 1984;311:438-42.

5 Turner WA, Critchley M. Respiratory disorders in epidemic encephalitis. Brain 1925;48:72-104.

6 Guilleminault C, Dement WC (Eds). Sleep apnea syndrome. Krock Foundation Series, vol 11. New York: Allen R Liss Inc., 1978.

7 Stradling JR. Controversies in sleep-related breathing disorders. Lung 1986;164:17-31.

Table Respiratory abnormalities in normals and patients during sleep

\begin{tabular}{|c|c|c|c|}
\hline Subjects & $\begin{array}{l}\text { Mean no of apnoeic* } \\
\text { episodes }\end{array}$ & $\begin{array}{l}\% \text { of apnoeic episodes of } \\
\text { obstructive/mixed nature }\end{array}$ & $\begin{array}{l}\text { Mean no of } \\
\text { desaturation } \dagger \text { "dips" }\end{array}$ \\
\hline $\begin{array}{l}\text { Normals }(n=20) \\
\text { Group 1: PD untreated } \\
(n=4)\end{array}$ & $\begin{array}{l}10 \cdot 8 \\
24\end{array}$ & $\begin{array}{r}9 \\
93\end{array}$ & $\begin{array}{l}0 \cdot 7 \\
3\end{array}$ \\
\hline $\begin{array}{l}\text { Group 2: PD treated } \\
(\mathrm{n}=6)\end{array}$ & $48 \cdot 5$ & $83 \cdot 5$ & 26 \\
\hline Group 3: $\operatorname{PEP}(n=10)$ & $29 \cdot 7$ & 81 & 9 \\
\hline
\end{tabular}

*Significant apnoea is defined as a cessation of nasal airflow for greater than or equal to $10 \mathrm{~s}^{6}$ †Significant arterial oxygen desaturation "dips" defined as a greater than or equal to $4 \%$ fall in oxygen saturation. ${ }^{6}$

PD = Parkinson's disease. PEP = post-encephalitic Parkinsonism.

References

1 Dewar J, Lunt H, Abernethy DA, Dady P, Haas LF. Cisplatin neuropathy with Lhermitte's sign. J Neurol Neurosurg Psychiatry 1986;49:96-9.

2 Thompson SW, Davis LE, Kornfield $M$, Hilgers RD, Standefer JC. Cisplatin neu- N ropathy, clinical, electrophysiologic, morphologic and toxicologic studies. Cancer 1984;54:1269-75.

3 Walsh TJ, Clark AW, Parhad IM, Green WR Neurotoxic effects of cisplatin therapy. Arch Neurol 1982;39:719-20.

\section{Cisplatin neuropathy with Lhermitte's sign}

Dewar et $a l^{1}$ and Thompson et al, ${ }^{2}$ three patients with cancer in whom the only drug in common was cisplatin and who do not appear to have metastatic disease. Our ho obvious signs of a neuropathy. The Lhermitte's phenomeno roved even when the neuropathy did $\equiv$ column dorsal gically examined case ${ }^{3}$ is all second-믈 an example of the dorsal root ganglia and $\frac{5}{\partial}$ We write to report another symptom in this situation that is normally associated with a primary demyelination in the spinal cord: $\overrightarrow{0}$ This patient is aged 38 years and developed an undifferentiated teratoma in his anterior $\Phi$ mediastinum. He was treated with surgery At the end of the course he described Lhermitte's phenomenon that lasted for a few weeks, and also a more permanent tingling. he ran about $\frac{q}{\omega}$ and he would become unsteady. ination at rest showed absent reflexes, m definite sensory loss and his gait was nof $Z$ joint position sense testing of his toes arf came unsteady, and this was worse when did not occur in a hot bath. His symptoms not progressed over 12 months and so $\vec{c}$ and think that they are related

Unlike Lhermitte's phenomenon which is rather non-specific for all sorts of causes of symptoms on exercise in this fashion is very multiple sclerosis and it is AC WILLIAMS CULLEN Hospital, Edgbaston, Birmingham B15 2TH, UK 